\title{
Interaction between Facilitation and Depression at a Large CNS Synapse Reveals Mechanisms of Short-Term Plasticity
}

\author{
Martin Müller, ${ }^{\star}$ Juan D. Goutman, ${ }^{\star}$ Olexiy Kochubey, and Ralf Schneggenburger \\ Laboratory of Synaptic Mechanisms, Brain-Mind Institute, École Polytechnique Fédérale de Lausanne (EPFL), 1015 Lausanne, Switzerland
}

The two fundamental forms of short-term plasticity, short-term depression and facilitation, coexist at most synapses, but little is known about their interaction. Here, we studied the interplay between short-term depression and facilitation at calyx of Held synapses. Stimulation at a "low" frequency of 10 or $20 \mathrm{~Hz}$, which is in the range of the spontaneous activity of these auditory neurons in vivo, induced synaptic depression. Surprisingly, an instantaneous increase of the stimulation frequency to $100 \mathrm{or} 200 \mathrm{~Hz}$ following the low-frequency train uncovered a robust facilitation of EPSCs relative to the predepressed amplitude level. This facilitation decayed rapidly $(\sim 30 \mathrm{~ms})$ and depended on presynaptic residual $\mathrm{Ca}^{2+}$, but it was not caused by $\mathrm{Ca}^{2+}$ current facilitation. To probe the release probability of the remaining readily releasable vesicles following the low-frequency train we made presynaptic $\mathrm{Ca}^{2+}$ uncaging experiments in the predepressed state of the synapse. We found that low-frequency stimulation depletes the fast-releasable vesicle pool (FRP) down to $\sim 40 \%$ of control and that the remaining FRP vesicles are released with $\sim 2$-fold slower release kinetics, indicating a hitherto unknown intrinsic heterogeneity among FRP vesicles. Thus, vesicles with an intrinsically lower release probability predominate after low frequency stimulation and undergo facilitation during the onset of subsequent high-frequency trains. Facilitation in the predepressed state of the synapse might help to stabilize the amount of transmitter release at the onset of high-frequency firing at these auditory synapses.

\section{Introduction}

The strength of synaptic transmission can vary during repetitive presynaptic activity and depends heavily on the previous activity of a synapse (Zucker and Regehr, 2002). Presynaptic spike trains can cause either a transient decrease or a transient increase in the strength of synaptic transmission. These two elementary forms of synaptic short-term plasticity-termed depression and facilitation-coexist at most synapses, but relatively little is known about how both forms of plasticity can interact with each other.

The calyx of Held, a large glutamatergic synapse located in the auditory brainstem circuit that computes sound-source localization, shows depression over a wide range of stimulation frequencies (Borst et al., 1995; von Gersdorff et al., 1997; Wang and Kaczmarek, 1998; Iwasaki and Takahashi, 2001). Depletion of a pool of readily releasable vesicles is regarded as the major mechanism underlying presynaptic forms of depression (Liley and North, 1953; von Gersdorff et al., 1997; Foster and Regehr, 2004), but it has also been proposed that depression is caused by a reduction of the release probability of any given readily releasable vesicle (Betz, 1970; Wu and Borst, 1999). Due to its large size, the

\footnotetext{
Received Sept. 4, 2009; revised Nov. 9, 2009; accepted Dec. 10, 2009.

This work was supported by Swiss National Science Foundation (3100A0-114069) and by the European Commission Coordination Action ENINET (contract number LSHM-CT-2005-19063).

${ }^{*}$ M.M and J.D.G. contributed equally to this work.

Correspondence should be addressed to Ralf Schneggenburger at the above address. E-mail: ralf.schneggenburger@ epfl.ch.

M. Müller's present address: Department of Biochemistry and Biophysics, University of California, San Francisco, CA 94158.

J. D. Goutman's present address: Instituto de Investigaciones en Ingeniería Genética y Biología Molecular, Universidad Buenos Aires-Consejo Nacional de Investigaciones Científicas y Técnicas, 1428 Buenos Aires, Argentina.

DOI:10.1523/JNEUROSCI.4378-09.2010

Copyright $\odot 2010$ the authors $\quad 0270-6474 / 10 / 302007-10 \$ 15.00 / 0$
}

calyx of Held affords an optimal experimental access to study presynaptic mechanisms of transmitter release and short-term plasticity. Studies using presynaptic voltage-clamp or $\mathrm{Ca}^{2+}$ uncaging combined with EPSC deconvolution have shown that prolonged presynaptic $\mathrm{Ca}^{2+}$ stimuli induce a fast and a slow release component, demonstrating that the readily releasable pool can be subdivided into a fast-releasable vesicle pool (FRP) and a slowly releasable vesicle pool (SRP) (Sakaba and Neher, 2001; Wadel et al., 2007; Wölfel et al., 2007). The fast release component at the calyx of Held, which has a half-width of only $\sim 0.5 \mathrm{~ms}$ (Schneggenburger and Neher, 2000; Taschenberger et al., 2005) is thought to be carried exclusively by FRP vesicles (Sakaba, 2006). However, it is unknown whether a heterogeneity of release probabilities between vesicles that carry action potential (AP)-driven release influences the short-term plasticity behavior of synapses, as postulated in a theoretical study (Trommershäuser et al., 2003). Also, the calyx of Held is not a purely depressing synapse, as facilitation can be uncovered under conditions of artificially lowered release probability (Felmy et al., 2003; Müller et al., 2007). However, the relevance of facilitation at this and other depressing synapses has remained unclear.

In most studies, the short-term plasticity of CNS synapses has been studied by using trains of stimuli applied after relatively long stimulation pauses (tens of seconds). However, in vivo, neurons in the auditory brainstem fire spontaneously at a mean frequency of $\sim 10-30 \mathrm{~Hz}$ even in the absence of sound, and sound stimulation can transiently increase AP frequency to several hundred hertz (Sommer et al., 1993; Kopp-Scheinpflug et al., 2003; Hermann et al., 2007; Sonntag et al., 2009). In the present study, we used the most basic stimulation protocol designed to mimic the effect of spontaneous AP firing on short-term plasticity: a 
brief low-frequency train $(10$ or $20 \mathrm{~Hz})$ to predepress synaptic transmission, followed immediately by a high-frequency train (see also Hermann et al., 2007). When applying this protocol to calyx of Held synapses in slices of young rats, we found that high-frequency trains $(100-200 \mathrm{~Hz})$ caused robust facilitation of transmitter release relative to the predepressed level. This facilitation in the predepressed state of the synapse is caused by a presynaptic $\mathrm{Ca}^{2+}$-dependent facilitation mechanism that acts on a partially depleted FRP in which vesicles with $\sim 2$-fold slowed release kinetics remain.

\section{Materials and Methods}

Slice preparation and electrophysiology. Transverse brainstem slices containing the medial nucleus of the trapezoid body (200 $\mu \mathrm{m}$ thickness) were prepared from 8- to 10-day-old Wistar rats using a Leica VT1200 slicer. Animal handling and experimental procedures were approved by the Veterinary Office of the Canton of Vaud, Lausanne, Switzerland. The extracellular solution contained the following (in $\mathrm{mm}$ ): $125 \mathrm{NaCl}, 25$ $\mathrm{NaHCO}_{3}, 2.5 \mathrm{KCl}, 1.25 \mathrm{NaH}_{2} \mathrm{PO}_{4}, 1 \mathrm{MgCl}_{2}, 2 \mathrm{CaCl}_{2}, 25$ glucose, 0.4 ascorbic acid, 3 myo-inositol, and 2 Na-pyruvate, $\sim 320$ mOsm, pH 7.4 when bubbled with carbogen gas $\left(95 \% \mathrm{O}_{2}, 5 \% \mathrm{CO}_{2}\right)$. For afferent fiber stimulation experiments (See Figs. 1, 2, and supplemental Figs. 1, 2, available at www.jneurosci.org as supplemental material), $100 \mu \mathrm{M} \mathrm{cy-}$ clothiazide (CTZ; Tocris Bioscience), $2 \mathrm{~mm} \gamma$-D-glutamylglycine $(\gamma$ DGG), $10 \mu \mathrm{m}$ bicuculine, and, in some experiments, $2 \mu \mathrm{M}$ strychnine were added to the extracellular solution. For paired presynaptic and postsynaptic recordings (see Figs. 3-6), we added $100 \mu \mathrm{M} \mathrm{CTZ,} 2 \mathrm{~mm}$ $\gamma$-DGG, 10 mm tetraethylammonium chloride (TEA-Cl), $1 \mu \mathrm{M}$ tetrodotoxin, and $50 \mu \mathrm{M} \mathrm{D}-2$-amino-5-phosphonovaleric acid (D-APV) to the extracellular solution. The intracellular solution used for most presynaptic and postsynaptic recordings contained the following (in $\mathrm{mm}$ ): 135 Cs-gluconate, 20 TEA-Cl, 10 HEPES, $5 \mathrm{Na}_{2}$-phosphocreatine, 4 MgATP, $0.3 \mathrm{Na}_{2} \mathrm{GTP}$. To this solution, $5 \mathrm{~mm}$ EGTA was added for postsynaptic recordings or $75 \mu \mathrm{M}$ EGTA for presynaptic recordings. For the $\mathrm{Ca}^{2+}$ imaging experiments, fura-2, EGTA, and fura-6F were added to the Csbased intracellular solution at the indicated concentrations (see Fig. 4). The presynaptic solution for the $\mathrm{Ca}^{2+}$ uncaging experiments (see Fig. 6) contained the following (in $\mathrm{mM}$ ): 120 Cs-gluconate, $20 \mathrm{TEA}-\mathrm{Cl}, 20$ HEPES, $5 \mathrm{Na}_{2} \mathrm{ATP}, 0.3 \mathrm{Na}_{2} \mathrm{GTP}, 1.5$ DM-nitrophen, $1.2 \mathrm{CaCl}_{2}, 0.4$ $\mathrm{MgCl}_{2}$, and 0.1 fura-2FF. All experiments were conducted at room temperature $\left(21-24^{\circ} \mathrm{C}\right)$.

Presynaptic and postsynaptic whole-cell recordings were made from calyx of Held synapses using an EPC-10/2 double patch-clamp amplifier (HEKA Elektronik). Series resistances $\left(R_{\mathrm{s}}\right)$ were $15-30 \mathrm{M} \Omega$ (55\% compensation) during presynaptic recordings and 3-10 $\mathrm{M} \Omega$ (compensation up to $90 \%$ ) during postsynaptic recordings. The remaining $\mathrm{R}_{\mathrm{s}}$ error of postsynaptic currents was corrected by an off-line routine (Meyer et al., 2001). Presynaptic $\mathrm{Ca}^{2+}$ current traces are shown after a $\mathrm{p} / 5$ correction of leak and capacitive currents (see Figs. 3, 5, 6).

For afferent fiber stimulation, the presynaptic axons were stimulated with a custom-made platinum-iridium bipolar electrode that was placed close to the midline of the brainstem slice. Presynaptic and postsynaptic APs were first recorded extracellularly to preselect a synapse that was amenable to midline stimulation (Borst et al., 1995; Meyer et al., 2001). During paired recordings (see Figs. 3-6), the terminals were stimulated with trains of brief presynaptic depolarizing steps from -70 to $+28 \mathrm{mV}$. In each recording, the length of these steps (range, $0.8-2.5 \mathrm{~ms}$ across all cells) was chosen such that the resulting first EPSC amplitudes were in the range of 3-6 nA, similar to that observed after afferent fiber stimulation. Each train stimulation sweep was separated from the preceding one by at least $40 \mathrm{~s}$.

$\mathrm{Ca}^{2+}$ uncaging and $\mathrm{Ca}^{2+}$ imaging. Presynaptic $\mathrm{Ca}^{2+}$ uncaging was done similarly as described previously (Schneggenburger and Neher, 2000; Wölfel et al., 2007; Kochubey and Schneggenburger, 2010). Here, we used a SP20 flash lamp (Rapp Optoelectronic) with a brief flash (halfwidth, $0.45 \mathrm{~ms}$ ) that was coupled into a dual epifluoresence port (TILL Photonics) adapted to the microscope (Olympus BX $50 \mathrm{WI}$ ). The result- ing presynaptic $\left[\mathrm{Ca}^{2+}\right]_{\mathrm{i}}$ signal was imaged using fura-2FF (Invitrogen), which was excited at 350 and $380 \mathrm{~nm}$ by a monochromator (exposure time $5 \mathrm{~ms}$; Polychrome IV; TILL Photonics). The emitted fluorescence was detected by a 12 -bit CCD camera $(8 \times 15$ on-chip binning). The intensity of the flash was attenuated by neutral density (ND) filters aimed at producing $\left[\mathrm{Ca}^{2+}\right]_{i}$ elevations of similar amplitudes between control flashes and flashes following $20 \mathrm{~Hz}$ trains (see Fig. 6).

Images were analyzed off-line, and $\left[\mathrm{Ca}^{2+}\right]_{\mathrm{i}}$ was calculated from the background-corrected fluorescence ratios (350/380 nm) (Grynkiewicz et al., 1985). The necessary calibration constants were obtained from a calibration procedure that is described in detail by Kochubey and Schneggenburger (2010).

Data analysis and model calculations. Presynaptic $\mathrm{Ca}^{2+}$ currents were integrated to obtain $\mathrm{Ca}^{2+}$ charge values $\left(Q_{\mathrm{Ca}}\right)$ (for details, see Müller et al., 2008). The relative $\mathrm{Q}_{\mathrm{Ca}}$ facilitation during conditioned high-frequency trains ( 166 or $200 \mathrm{~Hz}$ ) (see Fig. 3C, bottom) was calculated by dividing the maximal $\mathrm{Q}_{\mathrm{Ca}}$ during the high-frequency train by the control $\mathrm{Q}_{\mathrm{Ca}}$ value, taken as the average of the first stimulus of the high-frequency train and the last stimulus of the preceding $20 \mathrm{~Hz}$ train. For "control" high-frequency trains, the maximal $\mathrm{Q}_{\mathrm{Ca}}$ was normalized to the first $\mathrm{Q}_{\mathrm{Ca}}$.

To analyze the EPSC amplitudes during stimulus trains, we fitted the decay of each EPSC with an exponential function that was extrapolated to the time corresponding to the minimum (the peak) of the next EPSC. The EPSC amplitude was then calculated as the difference between the peak and the corresponding point of the extrapolated fit to avoid an influence of the remaining current from the preceding EPSC on the estimation of EPSC amplitudes. For “conditioned” $200 \mathrm{~Hz}$ trains (see Fig. $1 A$ ), facilitation was calculated by first constructing a curve of EPSC amplitudes versus stimulus number (see Fig. 1C). Next, the values were normalized to the last two EPSCs preceding the high-frequency train to yield EPSC amplitude relative to the predepressed level (see Fig. $1 D$, red trace). Facilitation during the control high-frequency trains was calculated by normalizing to the first EPSC amplitude (Fig. $1 D$, black trace).

Transmitter release rates (see Figs. 5, 6) were extracted from EPSCs by EPSC deconvolution using the methods developed by Neher and Sakaba (2001). The deconvolution analysis assumed that miniature EPSCs (mEPSCs) with double-exponential decay (Schneggenburger and Neher, 2000) add linearly to produce evoked EPSCs, and the derived release rates were corrected for a current component created by glutamate spillover (Neher and Sakaba, 2001) (see below). In each cell, the parameters of the mEPSC decay were obtained from a double-exponential function that was fitted to the decay of small (1-2 nA) EPSCs evoked by brief presynaptic depolarizations. Under our experimental conditions (100 $\mu \mathrm{M} \mathrm{CTZ,}$ $2 \mathrm{~mm} \gamma$-DGG), the mEPSC amplitude was assumed to be $15 \mathrm{pA}$ across cells (Scheuss et al., 2002). The "residual" current caused by glutamate spill over was estimated by fitting with a simple model of glutamate diffusion (Neher and Sakaba, 2001) using parameters found through iterative deconvolution of EPSCs responses to "fitting protocols" (Neher and Sakaba, 2001, their Fig. 12). The release rates derived by this analysis were integrated to obtain cumulative release rate time courses without correction for an assumed refilling process. The traces of cumulative release were fitted with single exponentials, double exponentials, or combinations of exponentials and lines for 50-100 ms following the stimulus onset (for details, see Wölfel et al., 2007).

For the prediction of the fast release time constant as a function of $\left[\mathrm{Ca}^{2+}\right]_{\mathrm{i}}$ (see Fig. $6 \mathrm{D}$ ), $\mathrm{Ca}^{2+}$-dependent transmitter release was modeled by an allosteric model of $\mathrm{Ca}^{2+}$ binding and vesicle fusion (Lou et al., 2005). We assumed a single pool of fast-releasable vesicles (1500 vesicles) and drove the model with the previously calculated $\left[\mathrm{Ca}^{2+}\right]_{\mathrm{i}}$ waveform expected for the fast flash lamp (Kochubey et al., 2009) (20-80\% rise time of the resulting $\left[\mathrm{Ca}^{2+}\right]_{\mathrm{i}}$ step, $0.24 \mathrm{~ms}$ ), which was scaled to different $\left[\mathrm{Ca}^{2+}\right]_{\mathrm{i}}$ amplitudes. The following parameters were found: $k_{\text {on }}=1.25 \times$ $10^{8} \mathrm{M}^{-1} \mathrm{~s}^{-1} ; k_{\text {off }}=5600 \mathrm{~s}^{-1} ; b=0.26 ; l_{+}=2 \times 10^{-4} \mathrm{~s}^{-1} ;$ and $f=25$.

All data were analyzed using custom-written routines in IgorPro 5.0 (Wavemetrics). Results are reported as average \pm SEM. Statistical significance was assessed by Student's $t$ tests and accepted at $p<0.05$. 


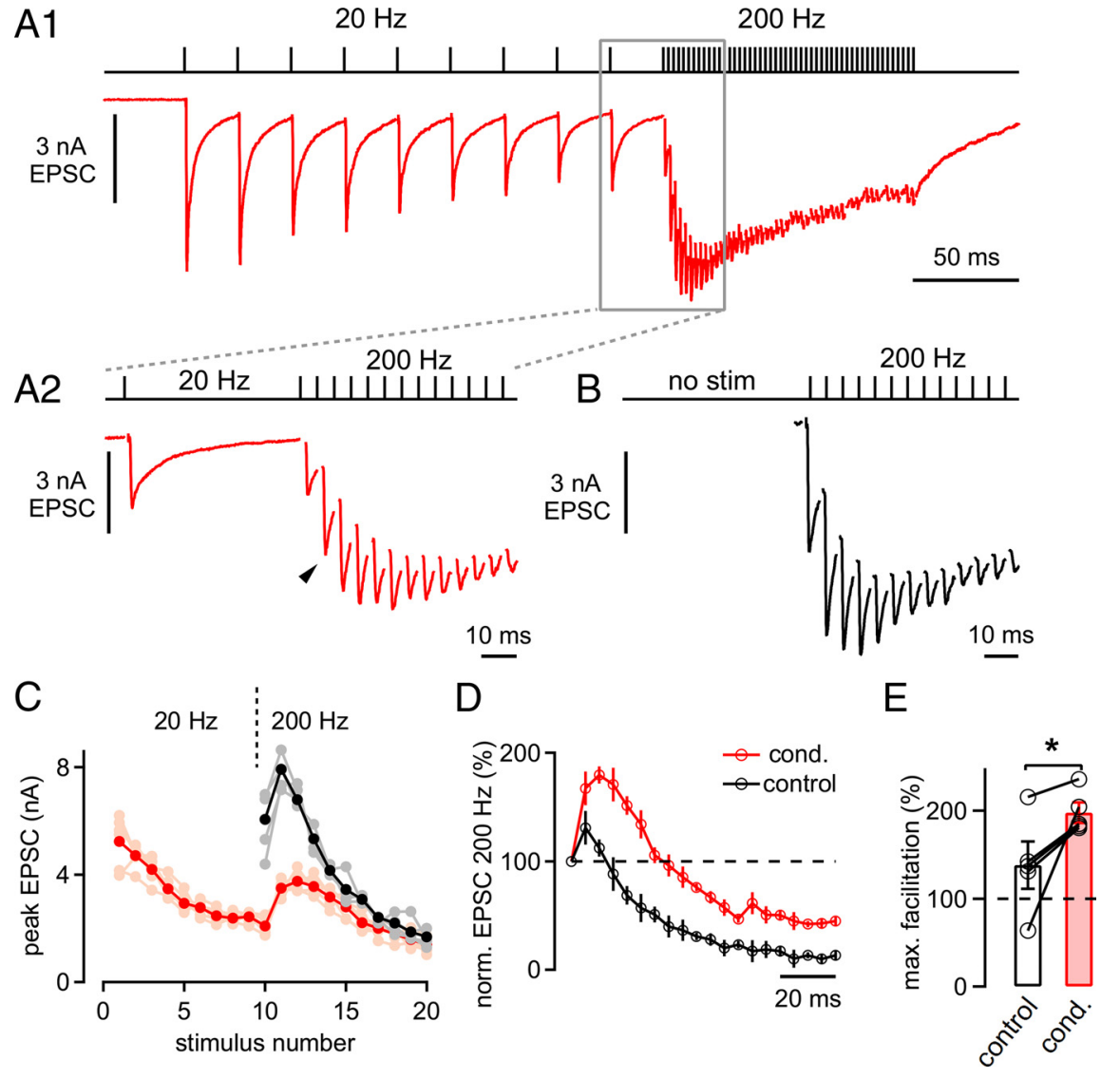

Figure 1. Facilitation in the predepressed state of the synapse. $A$, EPSC in response to 10 afferent fiber stimuli applied at $20 \mathrm{~Hz}$ followed by 30 stimuli at $200 \mathrm{~Hz}$. A2 shows the last EPSC during the low-frequency train and the beginning of the $200 \mathrm{~Hz}$ train (red trace) and corresponds to the boxed area in $A 1$. Note the pronounced facilitation of EPSCs early during the $200 \mathrm{~Hz}$ train. $B$, EPSCs in response to a $200 \mathrm{~Hz}$ train applied without a preceding $20 \mathrm{~Hz}$ train after a stimulation pause of $>45 \mathrm{~s}$. C, Mean and individual EPSC amplitudes of the $200 \mathrm{~Hz}$ trains that were preceded by $20 \mathrm{~Hz}$ trains (red and pink symbols, respectively) and the control $200 \mathrm{~Hz}$ trains (black and gray symbols). D, Normalized (norm.) average peak EPSC amplitudes of $200 \mathrm{~Hz}$ trains under control conditions (without preceding stimulation; black symbols) and immediately following $20 \mathrm{~Hz}$ trains (red symbols). Note the robust and long-lasting net facilitation observed during the conditioned $200 \mathrm{~Hz}$ train. Data in $\boldsymbol{A}-\boldsymbol{D}$ are from the same cell. $\boldsymbol{E}$, Average maximal (max.) facilitation during control $200 \mathrm{~Hz}$ trains (open bar) and during conditioned (cond.) $200 \mathrm{~Hz}$ trains that immediately followed $20 \mathrm{~Hz}$ stimulation (red bar; $n=5$ cells; $p=0.04$ ).

\section{Results}

\section{Short-term facilitation in the predepressed state of the synapse}

We investigated the short-term plasticity behavior of the calyx of Held synapse with a stimulus protocol in which a high-frequency train is preceded by a "conditioning" stimulus train of a lower frequency (10 or $20 \mathrm{~Hz}$; see Introduction). In the experiment shown in Figure $1 \mathrm{~A}$, we applied afferent fiber stimulation at 20 $\mathrm{Hz}$ that was immediately followed by a $200 \mathrm{~Hz}$ train. The $20 \mathrm{~Hz}$ train induced EPSC depression, such that the 10th EPSC was depressed to $38 \%$ of the first EPSC amplitude (Fig. 1A1); on average, depression was $27 \pm 5 \%$ of the control EPSC amplitude ( $n=5$ cells). When the stimulation frequency was instantaneously increased to $200 \mathrm{~Hz}$, we observed a pronounced facilitation of the EPSC amplitude early during the $200 \mathrm{~Hz}$ train (Fig. $1 A 2$, arrowhead). Maximal facilitation, which typically occurred during the second or third stimulus, was $198 \pm 11 \%$ of the first EPSC amplitude of the $200 \mathrm{~Hz}$ train (Fig. $1 \mathrm{E}$, right bar).

We next compared this facilitation in the predepressed state of the synapse with the response to a $200 \mathrm{~Hz}$ train applied after a long stimulation pause $(>40 \mathrm{~s})$, a condition that we will refer to as the "naive" state of the synapse (Fig. $1 B$ ). In plots of absolute and normalized EPSC amplitudes versus stimulus number, it can be seen that facilitation in the predepressed state was larger than that in the naive synapse (Fig. $1 C, D$ ). On average, the maximal facilitation in the naive state of the synapse was only $138 \pm 27 \%$ of control ( $n=5$ cells) (Fig. $1 E$, left bar), significantly smaller than facilitation in the predepressed state $(p=$ 0.04 ; see Fig. $1 E$, right bar). Also, facilitation in the predepressed state lasted longer than the relatively brief facilitation seen under control conditions (Fig. 1D).

The finding of a preferential facilitation in the partially depressed state of the synapse is unexpected in light of simple depletion models of depression (Liley and North, 1953; Weis et al., 1999; Foster and Regehr, 2004). If one assumes that depression during the $20 \mathrm{~Hz}$ train is exclusively mediated by depletion of synaptic resources, then one would expect to observe a faster rate of depression upon increasing of the stimulation frequency. Our observation of a robust facilitation during the onset of a high-frequency train might therefore indicate that not all readily releasable vesicles available to AP stimuli were released equally efficiently during the low-frequency train. In what follows, we will first investigate the mechanism of facilitation in the predepressed state of the synapse (see Figs. 2-4) and then address the question of why the release machinery in the predepressed state is more prone to facilitation as compared with the naive state (see Figs. 5, 6).

\section{Fast decay time of facilitation in the predepressed state}

High-frequency stimulation following a low-frequency train caused facilitation very effectively, whereas facilitation is nearly absent during 10 or $20 \mathrm{~Hz}$ trains (Fig. 1; see also supplemental Fig. 1, available at www.jneurosci.org as supplemental material). This is probably caused by a fast decay rate of facilitation, such that facilitation would only build up significantly during highfrequency trains. To test this prediction, we next measured the decay of facilitation in the predepressed state of the synapse by using a paired-pulse paradigm (Fig. 2). We predepressed synaptic transmission with a $10 \mathrm{~Hz}$ train of 10 stimuli and then applied an 11 th stimulus at a variable time interval $(\Delta t ; 4-100$ ms) (Fig. $2 A, B$ ). This protocol revealed strong facilitation at the shortest interval of $4 \mathrm{~ms}$ following the $10 \mathrm{~Hz}$ train, and facilitation then decayed back to the predepressed level of EPSC amplitudes within $\sim 50-100 \mathrm{~ms}$ (Fig. $2 B, C$ ). The decay of facilitation was approximated by exponential fits, yielding an average decay time constant of $28 \pm 5 \mathrm{~ms}(n=6$ cells) (Fig. $2 D)$. Thus, a fast-decaying facilitation mechanism increases the EPSC amplitude in the depressed state of the synapse, in between two subsequent stimuli applied at a "low" frequency of $\sim 10 \mathrm{~Hz}$.

When we probed the paired-pulse ratio of EPSC amplitudes in the naive state, we observed net paired-pulse depression at all 
A
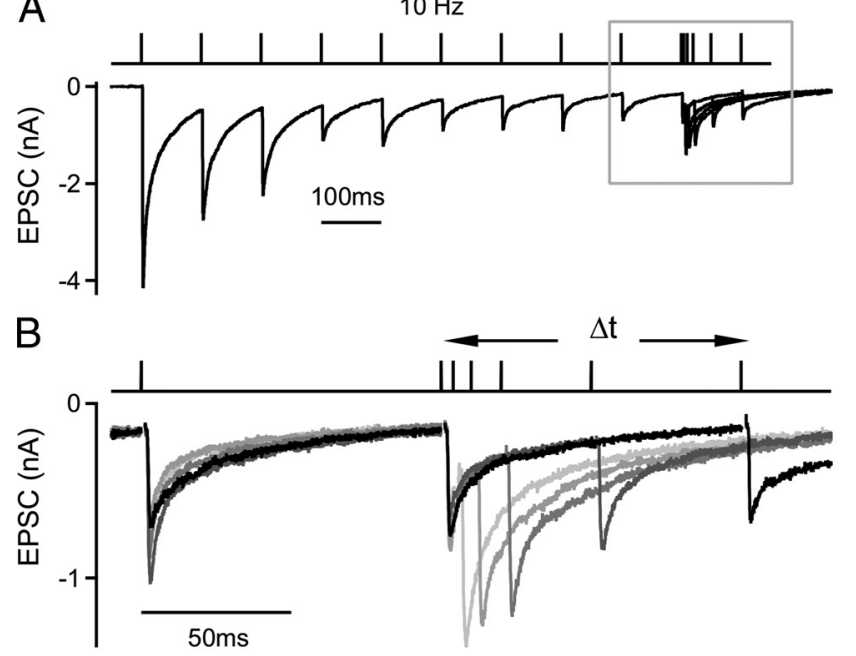

C

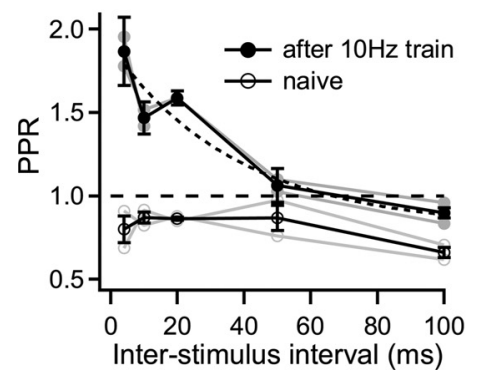

D

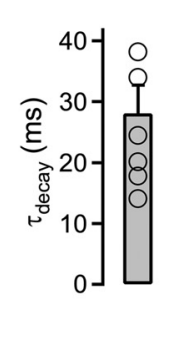

E

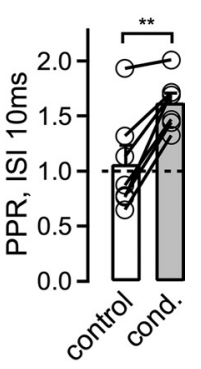

Figure 2. Decay kinetics of facilitation in the predepressed state of the synapse. $A$, The EPSC in response to a paired-pulse protocol that consisted of a $10 \mathrm{~Hz}$ train of 10 stimuli to predepress the synapse, followed by an 11th stimulus given at variable interpulse intervals (5-100 ms). $B$, The EPSC traces during the last stimulus at $10 \mathrm{~Hz}$ and during five different interstimulus intervals following the $10 \mathrm{~Hz}$ trains are shown at a higher time resolution (corresponding to the boxed area in $\boldsymbol{A}$ ). C, Average paired-pulse ratio (PPR; peak EPSC 11/peak EPSC 10) following the $10 \mathrm{~Hz}$ conditioning train (filled symbols) and for control conditions without preceding stimulation (open symbols). The decay of facilitation in the predepressed state (filled symbols) was fitted with an exponential function with a time constant of $38 \mathrm{~ms}$ (dashed line). Data in $\boldsymbol{A}-\mathbf{C}$ are from the same cell. $\boldsymbol{D}$, Mean decay time constant of facilitation recorded from $n=6$ cells. $\boldsymbol{E}$, Average paired-pulse ratio $(\Delta t=10 \mathrm{~ms})$ in response to two stimuli applied under control conditions (open bar, no preceding stimulation) or following the conditioning (cond.) $10 \mathrm{~Hz}$ train (gray bar). Note the significantly different paired-pulse ratio following $10 \mathrm{~Hz}$ trains ( $p=$ $0.0015 ; n=7$ cells).

intervals in the recording illustrated in Figure 2C (open symbols). At an interval of $10 \mathrm{~ms}$, the paired-pulse ratio was significantly larger in the predepressed state as compared with naive synapses (Fig. $2 E)(n=7$ cells; $p=0.0015)$. In a subset of the cells $(n=4$ cells, including the example in Fig. 2), the preceding low frequency train converted paired-pulse depression observed in the naive state to net paired-pulse facilitation. Thus, these experiments again show that facilitation is larger in the predepressed state as compared with the naive state (see also Fig. 1). Second, these experiments show that the underlying mechanism of facilitation has a fast decay time constant of $\sim 30 \mathrm{~ms}$.

\section{Facilitation in the depressed state is not mediated by $\mathrm{Ca}^{2+}$ current facilitation}

Activity-dependent changes of presynaptic $\mathrm{Ca}^{2+}$ currents have been proposed to play a role in short-term depression (Xu and $\mathrm{Wu}, 2005$ ) and in facilitation of transmitter release (Inchauspe et al., 2007; Mochida et al., 2008) (but see Müller et al., 2008). By employing paired presynaptic and postsynaptic whole-cell re- cordings, we next investigated whether facilitation in the predepressed state of the synapse could be caused by $\mathrm{Ca}^{2+}$ current facilitation. In these experiments (Fig. 3), transmitter release was evoked by brief AP-like presynaptic voltage-clamp steps to +28 $\mathrm{mV}$. The lengths of the steps (range, $0.8-2.5 \mathrm{~ms}$ in different cell pairs) were adjusted in each cell pair such that EPSCs of 3-6 nA were evoked, a similar amplitude range to EPSCs observed with afferent fiber stimulation (Fig. 1). A $20 \mathrm{~Hz}$ train of such brief depolarizations induced depression of EPSCs, followed by facilitation during the onset of the high-frequency train (Fig. $3 A, B$ ). In contrast, applying a high-frequency train alone induced net depression throughout the train (Fig. 3B, top, black symbols). In a plot of the relative EPSC amplitudes during the $200 \mathrm{~Hz}$ trains, it is seen that facilitation (relative to the first EPSC amplitude of the high-frequency train) was again much larger in the predepressed state than in the naive synapse (Fig. 3C, top, compare red and black data points). On average, the maximal facilitation in the predepressed state of the synapse was $197 \pm 16 \%(n=6$ cell pairs) (Fig. $3 \mathrm{D}$, right bar), whereas without the preceding $20 \mathrm{~Hz}$ train, high-frequency trains induced net depression of the second EPSC $(85 \pm 12 \%)$ (Fig. $3 D$, left bar) $(p<0.001)$. Thus, the preferential facilitation in the predepressed state of the synapse was also observed during paired presynaptic and postsynaptic recordings.

We next analyzed the $\mathrm{Ca}^{2+}$ current charge $\left(\mathrm{Q}_{\mathrm{Ca}}\right)$ for each step depolarization (see Materials and Methods) to assess the amount of $\mathrm{Ca}^{2+}$ current modulation. During low frequency stimulation, presynaptic $\mathrm{Ca}^{2+}$ currents showed cumulative inactivation down to $88 \pm 2 \%$ of control at the end of the $20 \mathrm{~Hz}$ train (Fig. $3 \mathrm{~B}$, left, bottom), confirming previous results in young rats $(\mathrm{Xu}$ and $\mathrm{Wu}$, 2005; Nakamura et al., 2008). During the subsequent highfrequency trains $(166 \mathrm{~Hz})$, the $\mathrm{Ca}^{2+}$ current charge partially recovered due to a slight $\mathrm{Ca}^{2+}$ current facilitation relative to the first pulse of the high-frequency train (Fig. 3B, bottom, right, compare step 1 and step 5 of the high-frequency train). However, the $\mathrm{Ca}^{2+}$ current facilitation was small, averaging $103 \pm 3 \%$ of the first $\mathrm{Ca}^{2+}$ current of the high-frequency train $(n=6$ paired recordings).

To estimate the influence of changes in $\mathrm{Ca}^{2+}$ currents on transmitter release, we took the relative $\mathrm{Ca}^{2+}$ current facilitation and elevated it to the power of 3.5 (Xu and $\mathrm{Wu}, 2005$; Müller et al., 2008). This showed that $\mathrm{Ca}^{2+}$ current facilitation alone does not predict a significant release facilitation (Fig. $3 C$, dashed red line). In addition, $\mathrm{Ca}^{2+}$ current facilitation was maintained during the highfrequency trains (Fig. 3C, bottom), whereas the EPSCs showed a sequence of facilitation followed by net depression after $\sim 10$ stimuli (Fig. 3C, top). Thus, $\mathrm{Ca}^{2+}$ current facilitation cannot explain the short-term plasticity of EPSCs seen during the onset of high-frequency trains in the predepressed synapse.

We also determined whether part of the EPSC depression seen during the conditioning low-frequency trains could be caused by $\mathrm{Ca}^{2+}$ current inactivation (Forsythe et al., 1998; Xu and $\mathrm{Wu}, 2005)$ by again taking the relative $\mathrm{Ca}^{2+}$ current to the 3.5 th power (Fig. $3 B$, dashed red line). This analysis suggests that $\mathrm{Ca}^{2+}$ current inactivation alone accounts for depression to $\sim 64 \%\left(0.88^{3.5}\right)$ at the end of the $20 \mathrm{~Hz}$ train, whereas the observed depression was much stronger (to $\sim 33 \%$ of control) (Fig. $3 B$, top). Therefore, a mechanism downstream of $\mathrm{Ca}^{2+}$ current inactivation, like depletion of readily releasable vesicles, is needed to fully explain the observed depression during low-frequency stimulation. Indeed, we show below that the pool of fastreleasable vesicles is depleted to $\sim 30-40 \%$ of control by a $20 \mathrm{~Hz}$ train (see Figs. 5, 6). 
A

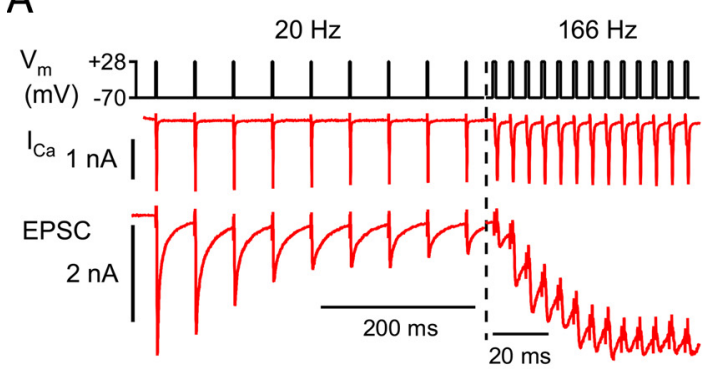

B
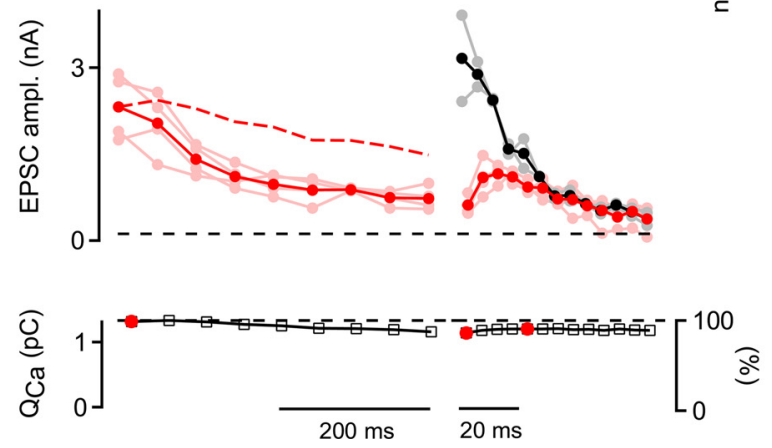

웅

Figure 3. Presynaptic $\mathrm{Ca}^{2+}$ current dynamics during facilitation in the predepressed state. $A$, Paired presynaptic and postsynaptic whole-cell recording (75 $\mu \mathrm{m}$ EGTA added to the presynaptic pipette solution). Presynaptic voltage-clamp protocol (top), presynaptic $\mathrm{Ca}^{2+}$ currents $\left(V_{\mathrm{c} ;}\right.$; middle), and EPSCS (bottom). Note the different time scales during the $20 \mathrm{~Hz}$ train and during the $166 \mathrm{~Hz}$ train. $B$, Average and individual peak EPSC amplitudes (ampl.) (top; dark and light symbols respectively) in response to the sequence of $20 \mathrm{~Hz}$ train followed by a high-frequency train (red) and to the control high-frequency trains (black). The bottom panel shows the average $\mathrm{Ca}^{2+}$ current integrals $\left(Q_{\mathrm{Ca}_{\mathrm{a}}}\right)$ during the conditioned high-frequency train. The dashed red trace (top) shows the depression of EPSCs predicted by the measured $\mathrm{Ca}^{2+}$ currents (calculated as the 3.5 th power of the relative $\mathrm{Q}_{\mathrm{Ca}}$; see Results). Note that $\mathrm{Ca}^{2+}$ current inactivation fails to predict the full magnitude of the observed EPSC depression. $C$, Average EPSC amplitudes (top) and $\mathrm{Ca}^{2+}$ current charge values (bottom) for the conditioned $200 \mathrm{~Hz}$ trains (red) and the control $200 \mathrm{~Hz}$ trains (black) normalized to the first response at $200 \mathrm{~Hz}$. Note that the $\mathrm{Ca}^{2+}$ current facilitation time courses were very similar for control and conditioned $200 \mathrm{~Hz}$ trains, whereas the short-term plasticity behavior differed considerably. The red dashed line shows the EPSC facilitation predicted by $\mathrm{Ca}^{2+}$ current facilitation. $D$, Average maximal (max.) facilitation during control $200 \mathrm{~Hz}$ trains (open bar) and during conditioned (cond.) $200 \mathrm{~Hz}$ trains (red bar; $n=6$ cell pairs; $p<0.001$ ).

\section{Facilitation in the predepressed state depends on presynaptic} residual $\left[\mathrm{Ca}^{2+}\right]_{\mathrm{i}}$

Paired-pulse facilitation (PPF) of transmitter release depends on the buildup of residual $\left[\mathrm{Ca}^{2+}\right]_{\mathrm{i}}$ in the nerve terminal (Katz and Miledi, 1968; Atluri and Regehr, 1996; Zucker and Regehr, 2002; Müller et al., 2007). To determine whether facilitation in the predepressed state is also caused by residual $\left[\mathrm{Ca}^{2+}\right]_{\mathrm{i}}$, we next imposed different conditions of presynaptic $\mathrm{Ca}^{2+}$ buffering by using EGTA or the fast $\mathrm{Ca}^{2+}$-buffer fura- 2 in the presynaptic patch pipette. Control measurements were done with a low concentration of EGTA $(75 \mu \mathrm{M})$ to mimic the intracellular mobile $\mathrm{Ca}^{2+}$ buffer present in calyces of Held (Müller et al., 2007) and with $100 \mu \mathrm{M}$ of the low-affinity $\mathrm{Ca}^{2+}$ indicator fura-6F to image $\left[\mathrm{Ca}^{2+}\right]_{\mathrm{i}}$. This $\mathrm{Ca}^{2+}$ buffer condition should not significantly influence the intracellular $\mathrm{Ca}^{2+}$ buffering strength of calyces of Held (Helmchen et al., 1997; Müller et al., 2007).

In these experiments, we again applied a $20 \mathrm{~Hz}$ train of brief presynaptic depolarizations to predepress the synapse, followed immediately by a $200 \mathrm{~Hz}$ train (Fig. 4A). With $75 \mu \mathrm{M}$ EGTA in the presynaptic patch pipette (control conditions), the spatially averaged $\left[\mathrm{Ca}^{2+}\right]_{\mathrm{i}}$ remained below $1 \mu \mathrm{M}$ during the $20 \mathrm{~Hz}$ train (Fig. $4 A$, top). When the stimulation frequency was increased to 200 $\mathrm{Hz}$, the spatially averaged $\left[\mathrm{Ca}^{2+}\right]_{\mathrm{i}}$ quickly rose and reached a value of $6.0 \pm 1.3 \mu \mathrm{M}$ at the end of the $200 \mathrm{~Hz}$ train ( $n=6$ cells) (Fig. 4A) (see also Korogod et al., 2005). Under these control conditions, the EPSCs transiently facilitated to $\sim 180 \%$ early dur- ing the $200 \mathrm{~Hz}$ train (Fig. 4A, bottom, arrow; $D$, black data points).

When we used $1 \mathrm{~mm}$ EGTA in the presynaptic patch pipette in addition to 100 $\mu \mathrm{M}$ fura- $6 \mathrm{~F}$, the buildup of spatially averaged $\left[\mathrm{Ca}^{2+}\right]_{\mathrm{i}}$ during the $20 \mathrm{~Hz}$ train was reduced, but during the onset of the highfrequency train, $\left[\mathrm{Ca}^{2+}\right]_{\mathrm{i}}$ increased almost as rapidly as it did under control conditions (Fig. $4 B$, top). Under these conditions, facilitation in the predepressed state was still observed (Fig. $4 B$, bottom, arrow; $D$, blue trace). Finally, we used fura-2 (1 $\mathrm{mm})$ to test the effect of a fast BAPTA-like $\mathrm{Ca}^{2+}$ buffer on synaptic facilitation. With $1 \mathrm{~mm}$ fura-2 (which was used to measure the presynaptic $\left[\mathrm{Ca}^{2+}\right]_{\mathrm{i}}$ at the same time), the increase in $\left[\mathrm{Ca}^{2+}\right]_{\mathrm{i}}$, as well as the facilitation during the high-frequency train, was strongly reduced (Fig. $4 C$, arrow, D, red trace). Averaged over all cells investigated with this protocol, we found that under control conditions ( $75 \mu \mathrm{M}$ EGTA; $n=6$ paired recordings) and with $1 \mathrm{~mm}$ EGTA ( $n=3$ pairs), facilitation during the onset of the $200 \mathrm{~Hz}$ train was large $(\sim 200 \%)$ and not significantly different (Fig. $4 E 1$, black and blue bars) $(p=$ 0.46). With $1 \mathrm{~mm}$ fura-2, however, facilitation was only $114 \pm 7 \%(n=5$ pairs $)$ of the first EPSC amplitude during the $200 \mathrm{~Hz}$ train, significantly smaller than under control conditions $(p=0.0016)$ (Fig. 4E1, red bar).

We next quantified the presynaptic $\left[\mathrm{Ca}^{2+}\right]_{\mathrm{i}}$ at the time point of maximal facilitation. Maximal facilitation usually occurred during the second, third, or fourth stimulus of the $200 \mathrm{~Hz}$ train. The $\left[\mathrm{Ca}^{2+}\right]_{\mathrm{i}}$ values at the time of maximal facilitation were $0.9 \pm 0.1 \mu \mathrm{M}, 0.68 \pm 0.1 \mu \mathrm{M}$, and $0.24 \pm 0.06 \mu \mathrm{M}$ for control, 1 mM EGTA, and $1 \mathrm{~mm}$ fura-2, respectively (Fig. 4 E2, black, blue, and red bar, respectively). Thus, the observation that 1 mM EGTA did not suppress facilitation in the predepressed state might be explained by the finding that EGTA did not strongly prevent the spatially averaged $\left[\mathrm{Ca}^{2+}\right]_{i}$ rise during the onset of the highfrequency train. In addition, the rise of $\left[\mathrm{Ca}^{2+}\right]_{\mathrm{i}}$ at the sites of vesicle fusion might be even less affected by the slowly binding $\mathrm{Ca}^{2+}$ buffer EGTA. These experiments show that facilitation in the predepressed state depends on the build-up of residual $\left[\mathrm{Ca}^{2+}\right]_{\mathrm{i}}$ in the nerve terminal. Overall, facilitation in the predepressed state of the synapse shares many properties with PPF studied at the calyx of Held (Felmy et al., 2003; Müller et al., 2008) (see Discussion).

\section{Vesicles remaining in the FRP have slower release kinetics}

We have established that during depression evoked by lowfrequency trains, facilitation of transmitter release can be more easily evoked (Figs. 1-4). What causes this increased susceptibility of the release machinery to short-term facilitation? Since facilitation can, in general, be observed more readily under conditions of lowered initial release probability (Zucker and Regehr, 2002), facilitation in the predepressed state of the synapse might indicate that those vesicles that remain in the readily releasable pool following low-frequency stimulation have a lower 
release probability. We therefore next probed the filling state of the readily releasable pool following $20 \mathrm{~Hz}$ trains, as well as the release kinetics of the remaining vesicles, by applying prolonged pooldepleting presynaptic depolarizations.

In simultaneous presynaptic and postsynaptic recordings, $20 \mathrm{~Hz}$ trains of brief depolarizations were followed by long ( 30 or $50 \mathrm{~ms}$ ) depolarizations to $0 \mathrm{mV}$, which should release the readily releasable pool (Fig. 5A) (Sakaba and Neher, 2001). As a control, pool-depleting stimuli were given in the naive state of the synapse (Fig. $5 B$, black traces). Following a $20 \mathrm{~Hz}$ train, the EPSC in response to the pool-depleting depolarization was reduced in amplitude (Fig. $5 B$, bottom, red trace), indicating that the 20 $\mathrm{Hz}$ train caused a partial depletion of the readily releasable pool. Interestingly, the EPSC in response to the pool-depleting depolarization following the $20 \mathrm{~Hz}$ train also had a slower rising phase, which was revealed more clearly by scaling the predepressed EPSC to the control EPSC (Fig. $5 B$, dashed red trace). The $20-80 \%$ rise time was $1.2 \mathrm{~ms}$ under control conditions and $1.6 \mathrm{~ms}$ following the $20 \mathrm{~Hz}$ train. On average, we found a significantly slowed $20-80 \%$ rise time (control: $1.4 \pm 0.4$ $\mathrm{ms}$; following the $20 \mathrm{~Hz}$ train: $2.0 \pm 0.5$ ms; $n=5$ cells; $p=0.008$, paired $t$ test). The prolonged rising phase of the EPSCs likely indicates slower release kinetics of vesicles that remain in the readily releasable pool following the low-frequency train.

To analyze the slowing of the transmitter release kinetics quantitatively, we deconvolved the EPSCs to obtain transmitter release rates (Schneggenburger and Neher, 2000; Neher and Sakaba, 2001) (see Fig. 5C, inset) and subse-

quently integrated the release rate traces (Fig. $5 C$ ). The resulting traces of cumulative release required double-exponential fits, demonstrating that release in response to prolonged presynaptic depolarizations occurred in a fast and a slow phase (Sakaba and Neher, 2001), likely mediated by the release of readily releasable vesicles of two distinct subpools, the FRP and the SRP. The number of vesicles released in the fast component was significantly reduced following predepression induced by the $20 \mathrm{~Hz}$ train (to $44 \pm 5 \%$ of control; $p<0.001$ ) (Fig. $5 D$ ). This indicates that depression induced by a $20 \mathrm{~Hz}$ train is, to a large part, caused by depletion of the FRP. At the same time, the release of the remaining FRP vesicles was slowed. We found that the time constant of the fast release component $\left(\tau_{\text {fast }}\right)$ was $3.0 \pm 0.8$ $\mathrm{ms}$ under control conditions and $4.0 \pm 0.8 \mathrm{~ms}$ after predepression, respectively (Fig. $5 E)$ ( $n=5$ pairs; $p=0.0098)$.

\section{Intrinsically decreased release kinetics of vesicles remaining} in the FRP

The slowing of release from the FRP following partial pool depletion by a $20 \mathrm{~Hz}$ train (Fig. 5) could indicate that low-frequency
C $1 \mathrm{mM}$ fura-2
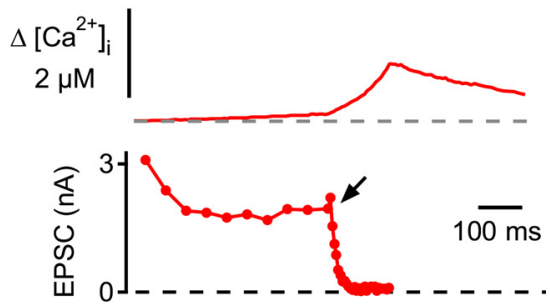

D

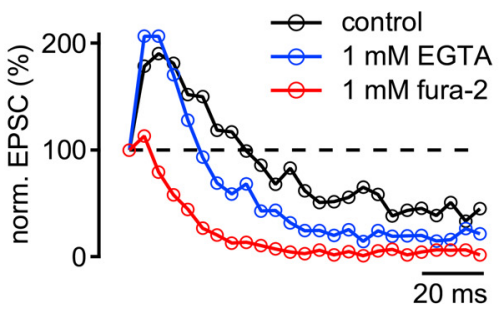

E1

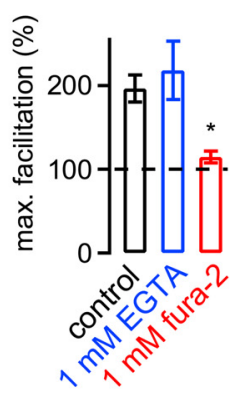

E2

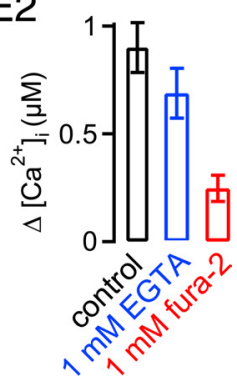

Figure 4. Facilitation in the predepressed state depends on presynaptic residual $\mathrm{Ca}^{2+} . \boldsymbol{A}$, Presynaptic spatially averaged [imaged by the low-affinity $\mathrm{Ca}^{2+}$ indicator fura-6F (top; average of $n=4$ traces), EPSCs (middle), and average peak EPSC mplitudes (bottom) in response to presynaptic voltage-clamp stimulation ( 10 stimuli at $20 \mathrm{~Hz}$, followed by 30 stimuli at $200 \mathrm{~Hz}$ ). pesynaptic solution contained $100 \mu \mathrm{m}$ fura-6F and $75 \mu \mathrm{m}$ EGTA. B, C, Presynaptic spatially averaged $\left[\mathrm{Ca}^{2+}\right]_{1}$ (top) and $\mathrm{Ca}^{2+}$ buffer fura-2. E1, E2, Average maximal (max.) facilitation (E1) and average $\left[\mathrm{Ca}^{2+}\right]_{\mathrm{i}}$ increase measured at the point of maximal facilitation during the $200 \mathrm{~Hz}$ train $\left(\Delta\left[\mathrm{Ca}^{2+}\right]_{\mathrm{i}}\right)(E 2)$. Black bars: $75 \mu \mathrm{m}$ EGTA and fura-6F ( $n=6$ paired recordings); blue bars: $1 \mathrm{~mm}$ EGTA and fura-6F ( $n=3$ pairs); red bars: $1 \mathrm{~mm}$ fura-2 ( $n=5$ pairs). Note that both the maximal facilitation and the increase in spatially averaged $\left[\mathrm{Ca}^{2+}\right]_{\mathrm{i}}$ were significantly smaller with $1 \mathrm{~mm}$ fura- 2 as compared with the two other conditions.

stimulation preferentially releases FRP vesicles with a high release probability, leaving behind FRP vesicles with slower release kinetics and, thus, lower release probabilities. Such a preexisting heterogeneity between FRP vesicles could be caused either by a differential colocalization of vesicles with respect to $\mathrm{Ca}^{2+}$ channels or by differences between the intrinsic release kinetics of FRP vesicles. To distinguish between these possibilities, we stimulated release by presynaptic $\mathrm{Ca}^{2+}$ uncaging, which generates a spatially homogeneous $\left[\mathrm{Ca}^{2+}\right]_{\mathrm{i}}$ signal in the nerve terminal (Naraghi et al., 1998; Wölfel et al., 2007). Therefore, if the observed slowing of the release kinetics is caused by intrinsic differences between FRP vesicles, then it should also be visible with $\mathrm{Ca}^{2+}$ uncaging.

In these experiments, a $20 \mathrm{~Hz}$ train of AP-like depolarizations was now followed by a $\mathrm{Ca}^{2+}$ uncaging stimulus to release the remaining readily releasable vesicles (Fig. $6 \mathrm{~A}$ ). In the example of Figure $6, \mathrm{Ca}^{2+}$ uncaging caused a presynaptic $\left[\mathrm{Ca}^{2+}\right]_{\mathrm{i}}$ step to $\sim 11 \mu \mathrm{M}$, as measured by the $\mathrm{Ca}^{2+}$ indicator fura-2FF (Fig. $6 \mathrm{~B}$, top), and evoked an EPSC with an amplitude of $\sim 4 \mathrm{nA}$ (Fig. $6 B$, bottom, red trace). A control flash given without a preceding 20 $\mathrm{Hz}$ train induced a comparable $\left[\mathrm{Ca}^{2+}\right]_{\mathrm{i}}$ step to $\sim 11 \mu \mathrm{M}$, which 
A
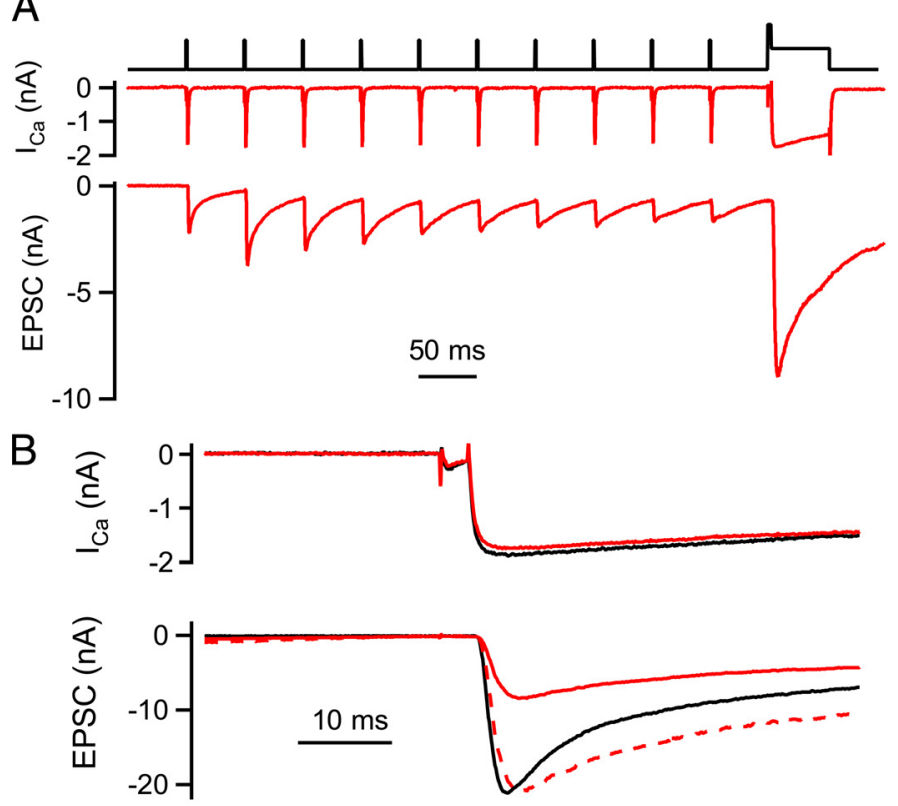

$\mathrm{C}$

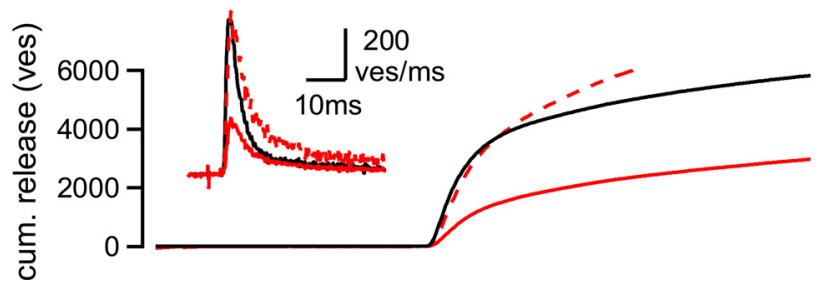

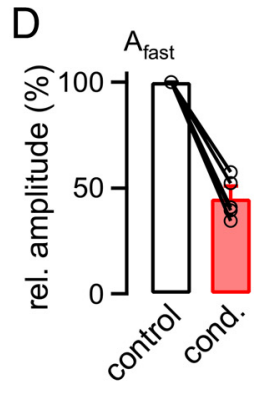

E

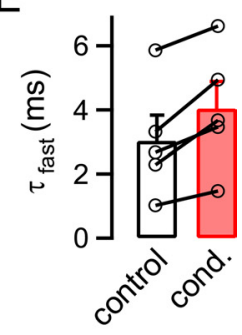

al., 2009). Following $20 \mathrm{~Hz}$ stimulation, the amplitude of the fast release component, which reflects release from the FRP, was significantly reduced from $1669 \pm$ 103 vesicles under control conditions to $652 \pm 82$ vesicles following the $20 \mathrm{~Hz}$ train ( $n=17$ cell pairs with $\mathrm{Ca}^{2+}$ uncaging; $p<$ $0.001)$. In addition, in the example of Figure $6 A-C$, the fast-release time constant was $1.9 \mathrm{~ms}$ for the control flash but only $3.4 \mathrm{~ms}$ for the flash given after the conditioning $20 \mathrm{~Hz}$ train (Fig. 6C, compare black and red cumulative release traces). This suggests that the FRP vesicles that remain after $20 \mathrm{~Hz}$ stimulation have intrinsically slower release kinetics.

The transmitter release time constant shows a steep inverse dependency on $\left[\mathrm{Ca}^{2+}\right]_{\mathrm{i}}$ (Heinemann et al., 1994; Wölfel et al., 2007). Since it was not always possible to achieve identical postflash $\left[\mathrm{Ca}^{2+}\right]_{\mathrm{i}}$ values for control conditions and following the $20 \mathrm{~Hz}$ trains, we next plotted the fast release time constants as a function of the postflash $\left[\mathrm{Ca}^{2+}\right]_{\mathrm{i}}$ for all cell pairs investigated here (Fig. $6 D$, closed and open symbols for control and conditioned responses, respectively). This plot shows, first, that the fast release time constant is steeply dependent on $\left[\mathrm{Ca}^{2+}\right]_{\mathrm{i}}$. Second, most of the data points following the 20 $\mathrm{Hz}$ train are shifted toward larger time constants (Fig. 6D, compare open and closed symbols). To analyze this shift more carefully, we first fitted the relationship between the fast release time constant and $\left[\mathrm{Ca}^{2+}\right]_{i}$ with a model of $\mathrm{Ca}^{2+}$ binding and vesicle fusion (Fig. $6 D$, line) (see Materials and Methods). We then computed the ratio between the data points and the fit line (Fig. 6E). In this plot, the control data points fluctuated around the

evoked an EPSC of $\sim 13 \mathrm{nA}$ amplitude (Fig. $6 B$; black traces). In this recording, comparable $\left[\mathrm{Ca}^{2+}\right]_{\mathrm{i}}$ steps under both conditions, despite the preceding $\mathrm{Ca}^{2+}$ influx during the conditioning $20 \mathrm{~Hz}$ train, were achieved by controlling the flash light intensity with neutral density filters (see Materials and Methodss). In addition to causing a decrease in the flash-evoked EPSC amplitude, the 20 $\mathrm{Hz}$ stimulation led to a slowing of the EPSC rise time, which was revealed more clearly by scaling the conditioned EPSC trace to the peak of the control EPSC (Fig. $6 \mathrm{~B}$, dotted red trace). In this example, the $20-80 \%$ rise time of the flash-evoked EPSC was $0.84 \mathrm{~ms}$ under control conditions and $1.28 \mathrm{~ms}$ following the conditioning $20 \mathrm{~Hz}$ train. This suggests that the heterogeneity between the FRP vesicles found with presynaptic depolarizations (see above) (Fig. 5) is caused by intrinsic differences between FRP vesicles.

To analyze the slowing of the fast release component in more detail, we deconvolved the flash-evoked EPSCs to derive transmitter release rates and traces of cumulative release (Fig. 6C). The large majority of the cumulative release traces required doubleexponential fits, indicating that $\mathrm{Ca}^{2+}$ uncaging evoked both a fast and a slow release component (Wölfel et al., 2007; Kochubey et fit prediction, as expected (Fig. $6 E)(0.92 \pm 0.05$ fold; $n=33$ flashes). On the contrary, the data obtained in the predepressed state of the synapse were on average $1.85 \pm 0.16$-fold slower (Fig. $6 E$, open data points; $n=28$ flashes) (Fig. $6 E$, red average data points). The difference between the relative time constant following $20 \mathrm{~Hz}$ stimulation and a hypothetical value of 1 was highly significant $\left(p<10^{-5}\right.$; one-sample Student's $t$ test). In addition, we separately analyzed the absolute fast release time constants $\left(\tau_{\text {fast }}\right)$ for two ranges of postflash $\left[\mathrm{Ca}^{2+}\right]_{\mathrm{i}}($ Fig. $6 \mathrm{~F})$. This analysis again revealed a significant increase of $\tau_{\text {fast }}$ following the conditioning $20 \mathrm{~Hz}$ trains for both $\left[\mathrm{Ca}^{2+}\right]_{\mathrm{i}}$ ranges (Fig. $\left.6 F\right)(p=0.002$ and 0.01).

Taken together, the $\mathrm{Ca}^{2+}$ uncaging data demonstrate that 20 $\mathrm{Hz}$ trains lead to a partial depletion of the FRP, and that the release kinetics of the remaining FRP vesicles (approximately one-third of all FRP vesicles) are intrinsically slower by a factor of $\sim 2$ with respect to control. These findings indicate that following low-frequency stimulation, FRP vesicles with a lower release probability remain and then likely undergo facilitation during the onset of a subsequent high-frequency train. 


\section{Discussion}

We found that a depressing synapse, the calyx of Held, shows robust facilitation of transmitter release at the onset of highfrequency trains, given that the synapse was predepressed by a preceding lowfrequency train $(\sim 10-20 \mathrm{~Hz})$. Since facilitation is, in general, observed more readily under conditions of low release probability, the increased facilitation in the predepressed state indicates a lower release probability of those vesicles that remain in the readily releasable pool. We show that facilitation in the depressed state of the synapse was not caused by $\mathrm{Ca}^{2+}$ current facilitation but depended on the buildup of residual free $\left[\mathrm{Ca}^{2+}\right]_{\mathrm{i}}$ in the nerve terminal. A key observation was that following low-frequency trains, the rise time of EPSCs evoked by pooldepleting depolarizations and by $\mathrm{Ca}^{2+}$ uncaging stimuli was slowed, indicating that vesicles with slower intrinsic release kinetics remained after partial depletion of the FRP. Thus, heterogeneity of release probabilities between readily releasable vesicles, together with a $\mathrm{Ca}^{2+}$. dependent facilitation mechanism, allows the synapse to recruit extra synaptic strength at the transition from low- to high-frequency activity.

\section{Mechanism of facilitation in the depressed state of the synapse}

The facilitation in the predepressed state of the synapse that we discovered here shared many properties with paired-pulse facilitation of transmitter release that can be observed under conditions of reduced initial release probability at the calyx of Held. Thus, facilitation in the predepressed state had an amplitude of $\sim 150$ $200 \%$ of control (Figs. 1-4), only slightly smaller than that of paired-pulse facilitation studied under reduced initial release probability ( $\sim 200-220 \%)$ (Müller et al., 2007). Second, the decay time constant of facilitation in the predepressed state was fast $(28 \mathrm{~ms})$ (Fig. 2), similar to that of paired-pulse facilitation $(\sim 30 \mathrm{~ms})$ (Müller et al., 2007). Third, facilitation was strongly suppressed by adding the fast, BAPTA-like $\mathrm{Ca}^{2+}$ buffer fura- 2 to the presynaptic nerve terminal (Fig. 4). This shows that facilitation in the predepressed state is caused by a presynaptic mechanism and depends on the buildup of presynaptic residual $\left[\mathrm{Ca}^{2+}\right]_{\mathrm{i}}$, similarly as paired-pulse facilitation (Müller et al., 2008; Hori and Takahashi, 2009).

Previous work has suggested that facilitation of transmitter release could be, to a large part, mediated by $\mathrm{Ca}^{2+}$ current facilitation (Inchauspe et al., 2007; Mochida et al., 2008). In contrast, a recent study at the calyx of Held found only a limited contribution of $\mathrm{Ca}^{2+}$ current facilitation to paired-pulse facilitation ( $40 \%$
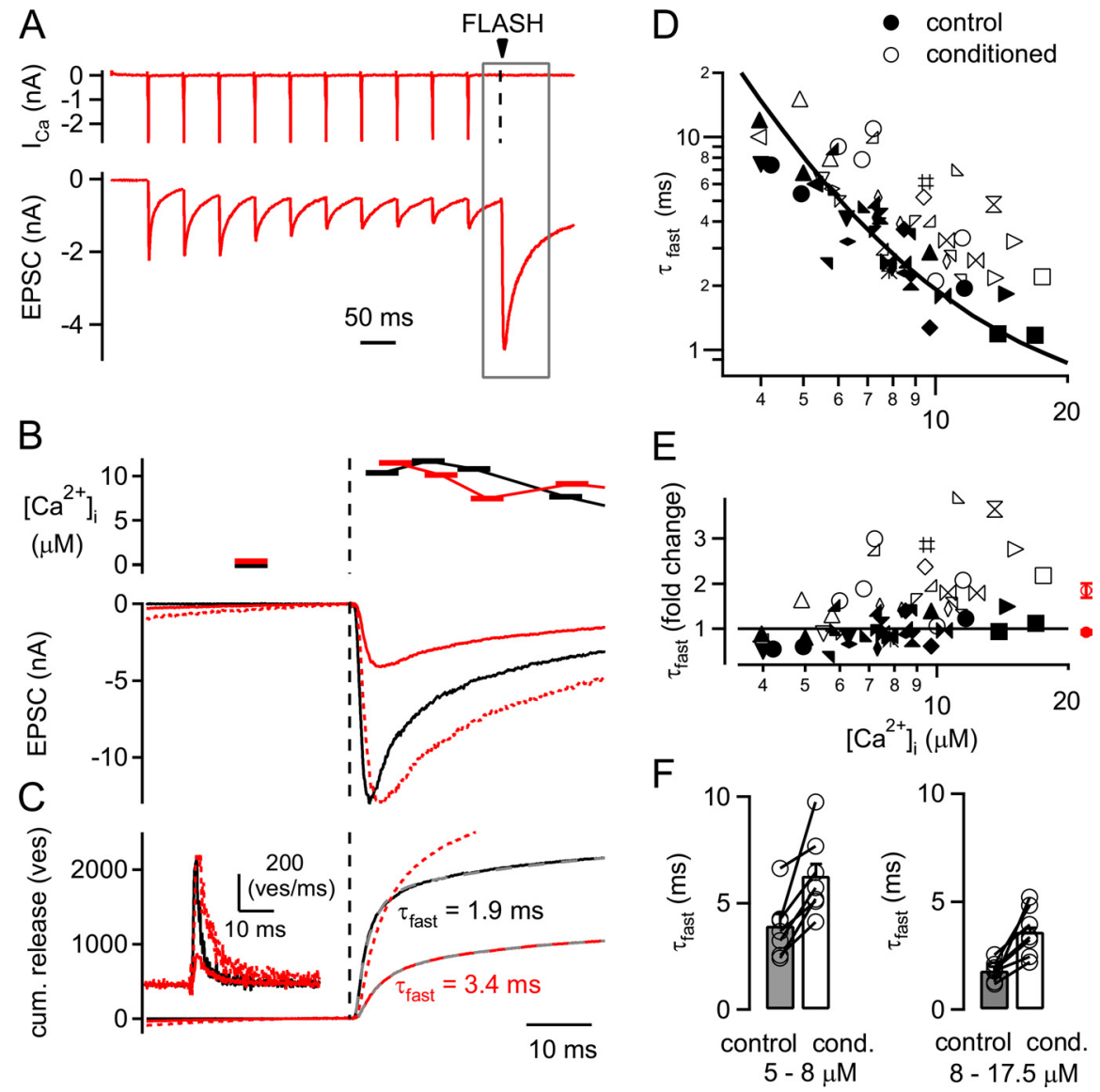

Figure 6. $\mathrm{Ca}^{2+}$ uncaging reveals a decreased intrinsic release kinetics of the remaining FRP vesicles (ves). $\boldsymbol{A}$, Presynaptic $\mathrm{Ca}^{2+}$ currents $\left(I_{\mathrm{Ca}}\right.$; top), and EPSCS (bottom) in response to a $20 \mathrm{~Hz}$ train followed by $\mathrm{Ca}^{2+}$ uncaging. B, Presynaptic $\left[\mathrm{Ca}^{2+}\right]_{\mathrm{i}}$ as imaged by fura-2FF (top) and EPSCs (bottom) in response to a flash applied to the naive synapse (black traces) and to the predepressed synapse (red traces). The predepressed EPSC was scaled to the peak of the naive EPSC (dashed red trace; note the slower rise phase of the predepressed EPSC). C, Transmitter release rates (inset) and cumulative (cum.) release traces of the EPSCs shown in $\boldsymbol{B}$. Double ential fits of the cumulative release traces are shown as gray dashed lines. Note the slower time constant of the fast release component $\left(\tau_{\text {fast }}\right)$ despite the similar post-flash $\left[\mathrm{Ca}^{2+}\right]_{i}$ step obtained in these examples (see $\left.\boldsymbol{B}\right)$. The cumulative release trace following the $20 \mathrm{~Hz}$ train was scaled (see red dashed trace) to match the amplitude of the fast release component $\left(A_{\text {fast }}\right)$ under conditions. $D$, Plot of the fast release time constants obtained from double exponential fits to cumulative release traces evoked by $\mathrm{Ca}^{2+}$ uncaging (see $\boldsymbol{C}$. Time constants of control flash responses and flashes following the conditioning $20 \mathrm{~Hz}$ train are shown as filled and open symbols, respectively. The relationship between fast time constants and $\left[\mathrm{Ca}^{2+}\right]_{\mathrm{i}}$ in response to control plots $\left[\mathrm{Ca}^{2+}\right]_{\mathrm{i}}$ (in $\left.\mu \mathrm{M}\right)$ as in $\boldsymbol{E}$. E, Plot of the fold change between the fast release time constants and the fit to the control data of the fast release time constants. Note that while the control data (filled symbols) fluctuate around a value of 1 as expected (filled mols), the $\tau_{\text {fast }}$ values following the $20 \mathrm{~Hz}$ trains (open symbols) show a robust $\sim 1.5-2$ fold slowing. The average values of all relative $\tau_{\text {fast }}$ values are shown as red average symbols for the control data and following the $20 \mathrm{~Hz}$ trains (red closed and open symbols, respectively). $\boldsymbol{F}$, Average fast-time constants ( $n=7$ cell pairs) separated for two ranges of postflash [ $\left.\mathrm{Ca}^{2+}\right]_{\mathrm{i}}$ values (left, 5-8 $\mu \mathrm{m}$; right, $8-17.5 \mu \mathrm{M}$ ), both under control conditions (gray bars), and following $20 \mathrm{~Hz}$ trains (open bars). Note the significant slowing of $\tau_{\text {fast }}$ for all paired comparisons ( $p=0.002$ and 0.01 for $5-8$ and $8-17.5 \mu \mathrm{m}\left[\mathrm{Ca}^{2+}\right]_{\mathrm{i}}$, respectively).

or less) and concluded that the majority of facilitation $(\sim 60 \%)$ is a process that tracks the rapid decay of residual $\left[\mathrm{Ca}^{2+}\right]_{\mathrm{i}}$ independently of $\mathrm{Ca}^{2+}$ current facilitation (Müller et al., 2008). Here, we observed only little presynaptic $\mathrm{Ca}^{2+}$ current facilitation when we increased the stimulation frequency from $20 \mathrm{~Hz}$ to $200 \mathrm{~Hz}$ (Fig. 3). Thus, facilitation in the predepressed state of the synapse is largely independent of $\mathrm{Ca}^{2+}$ current facilitation and is probably mediated by a fast-equilibrating, high-affinity $\mathrm{Ca}^{2+}$ binding site (Atluri and Regehr, 1996; Tang et al., 2000) and/or by $\mathrm{Ca}^{2+}$ buffer saturation (Blatow et al., 2003; Felmy et al., 2003) (Müller et al., 2008, their Discussion). The rapid decay kinetics of this facilitation mechanism $(\sim 30 \mathrm{~ms})$, which is caused by the fast decay of residual free $\left[\mathrm{Ca}^{2+}\right]_{\mathrm{i}}$ in the nerve terminal (Müller et al., 
2007), implies that short-term facilitation will only build up significantly when the stimulation frequency exceeds a value of $\sim 1 / \tau$ or $\sim 30 \mathrm{~Hz}$. This expectation was borne out in experiments with EGTA-AM, which selectively suppressed the facilitation component of short-term plasticity during high-frequency trains $(100 \mathrm{~Hz})$ but left short-term depression during $10 \mathrm{~Hz}$ stimulation largely unaffected (see supplemental Fig. 1, available at www. jneurosci.org as supplemental material). Thus, because of its fast decay kinetics, facilitation is well suited to detect an increase in synaptic activity from low to high frequency.

\section{Pool depletion and a shift toward more slowly releasable FRP vesicles}

Using pool-depleting depolarizations and $\mathrm{Ca}^{2+}$ uncaging, we showed that synaptic depression induced by $10-20 \mathrm{~Hz}$ trains leads to a partial depletion of the fast-releasable vesicle pool FRP (to $\sim 40 \%$ of control) (Fig. 5). At the same time, $\mathrm{Ca}^{2+}$ uncaging experiments demonstrated that the remaining FRP vesicles were released with a 1.5- to 2-fold slower intrinsic release kinetics (Fig. 6). Interestingly, a recent study found a frequency-dependent slowing of the EPSC rise time in fiber stimulation experiments (Fedchyshyn and Wang, 2007) that might be caused by the same mechanism. We interpret the slowing of the fast release component seen in $\mathrm{Ca}^{2+}$ uncaging experiments as evidence for a preexisting heterogeneity of release kinetics among FRP vesicles. We cannot entirely exclude, however, that adaptation of the release machinery could cause a slowing of the fast release component (see also Hsu et al., 1996; Wölfel et al., 2007). Regardless of the exact mechanism, slower release is expected to translate into lower release probability during AP stimulation. These remaining, more slowly releasable vesicles most likely undergo facilitation during the onset of a subsequent high-frequency train, in keeping with the idea that facilitation can be observed more easily under conditions of low release probability (Zucker and Regehr, 2002).

Previous work at the calyx of Held demonstrated that EPSCs that are evoked during the recovery phase following (partial) pool depletion have a slower rise time, indicating slowed release kinetics (Wu and Borst, 1999). Subsequently, Sakaba and Neher (2001) introduced EPSC deconvolution, which allowed them to distinguish between a fast and a slow component of release, likely driven by FRP and SRP vesicles. They concluded that the slowed EPSC rise time seen after partial pool depletion was caused by selective depletion of FRP vesicles relative to SRP vesicles (Sakaba and Neher, 2001, their Fig. 3), but they did not consider a slowing of the release kinetics of the FRP. Our findings indicate an additional heterogeneity among FRP vesicles. Thus, the slowing of depolarization-evoked EPSCs observed by Wu and Borst (1999) might be caused by two mechanisms: by a selective predepletion of FRP vesicles relative to SRP vesicles (Sakaba and Neher, 2001), as well as by an additional slowing of the remaining FRP vesicles (this study). The slowing of the release kinetics of FRP vesicles described here is highly relevant for AP-evoked release and its short-term plasticity, since FRP vesicles carry the phasic release during APs (Sakaba, 2006).

The recovery of very fast-releasable vesicles probably takes several seconds, as suggested by the slow recovery of the EPSC rise time and AP-induced EPSCs (Wu and Borst, 1999). Additional evidence for a slow process of maturation of high- $p$ vesicles comes from a knock-out study of Rab3 proteins in hippocampal neurons that suggested that Rab3 acts to increase the intrinsic release probability of readily releasable vesicles ("superpriming") (Schlüter et al., 2006). These findings, together with our results, suggest that some FRP vesicles can slowly mature into a very fast-releasable state. Changes of EPSC rise times or of the synaptic delay during short-term plasticity have also been observed at other synapses (Waldeck et al., 2000; Boudkkazi et al., 2007), indicating that heterogeneity of release kinetics might be important for short-term plasticity at various types of synapses.

\section{Possible relevance of facilitation at a depressing synapse}

It is intriguing to speculate about a role of facilitation for information processing at these auditory synapses. Although we mainly investigated young rats before the onset of hearing ([postnatal day 8 (P8) to P10], we also found a significant, albeit slightly weaker facilitation in the predepressed state of the synapse at P15-P17 (see supplemental Fig. 2, available at www.jneurosci.org as supplemental material), indicating that facilitation is also present in calyces of young hearing rats. It is possible, however, that a further developmental upregulation of $\mathrm{Ca}^{2+}$ binding proteins in calyces of Held (Felmy and Schneggenburger, 2004) could reduce the amount of facilitation with further development beyond P17.

Recent work has shown that synaptic depression observed after long stimulation pauses in slice preparations might be less relevant in vivo (Hermann et al., 2007; Lorteije et al., 2009), mainly because of the high rates of spontaneous firing. Our work suggests that sudden increases in the rate of afferent fiber firing during sound-evoked activity might induce facilitation in the predepressed state of the synapse similar to the facilitation observed here in slice recordings. Facilitation of EPSCs in the partially depressed state of the synapse could transiently compensate for the effect of depression, thereby stabilizing the transmitter output at the beginning of high-frequency activity. This facilitation is expected to counteract the increase of the delay and the temporal jitter of postsynaptic APs seen during high-frequency trains (Tolnai et al., 2009; Lorteije et al., 2009). However, more experimental work is needed to address the possible physiological implications of facilitation in the partially depressed state of synapses.

\section{References}

Atluri PP, Regehr WG (1996) Determinants of the time course of facilitation at the granule cell to Purkinje cell synapse. J Neurosci 16:5661-5671.

Betz WJ (1970) Depression of transmitter release at the neuromuscular junction of the frog. J Physiol 206:629-644.

Blatow M, Caputi A, Burnashev N, Monyer H, Rozov A (2003) $\mathrm{Ca}^{2+}$ buffer saturation underlies paired pulse facilitation in calbindin-D28kcontaining terminals. Neuron 38:79-88.

Borst JG, Helmchen F, Sakmann B (1995) Pre- and postsynaptic whole-cell recordings in the medial nucleus of the trapezoid body of the rat. J Physiol 489:825-840.

Boudkkazi S, Carlier E, Ankri N, Caillard O, Giraud P, Fronzaroli-Molinieres L, Debanne D (2007) Release-dependent variations in synaptic latency: a putative code for short- and long-term synaptic dynamics. Neuron 56:1048-1060.

Fedchyshyn MJ, Wang LY (2007) Activity-dependent changes in temporal components of neurotransmission at the juvenile mouse calyx of Held synapse. J Physiol 581:581-602.

Felmy F, Schneggenburger R (2004) Developmental expression of the $\mathrm{Ca}^{2+}$-binding proteins calretinin and parvalbumin at the calyx of Held of rats and mice. Eur J Neurosci 20:1473-1482.

Felmy F, Neher E, Schneggenburger R (2003) Probing the intracellular calcium sensitivity of transmitter release during synaptic facilitation. Neuron 37:801-811.

Forsythe ID, Tsujimoto T, Barnes-Davies M, Cuttle MF, Takahashi T (1998) Inactivation of presynaptic calcium current contributes to synaptic depression at a fast central synapse. Neuron 20:797-807.

Foster KA, Regehr WG (2004) Variance-mean analysis in the presence of a 
rapid antagonist indicates vesicle depletion underlies depression at the climbing fiber synapse. Neuron 43:119-131.

Grynkiewicz G, Poenie M, Tsien RY (1985) A new generation of $\mathrm{Ca}^{2+}$ indicators with greatly improved fluorescence properties. J Biol Chem 260:3440-3450.

Heinemann C, Chow RH, Neher E, Zucker RS (1994) Kinetics of the secretory response in bovine chromaffin cells following flash photolysis of caged $\mathrm{Ca}^{2+}$. Biophys J 67:2546-2557.

Helmchen F, Borst JG, Sakmann B (1997) Calcium dynamics associated with a single action potential in a CNS presynaptic terminal. Biophys J 72:1458-1471.

Hermann J, Pecka M, von Gersdorff H, Grothe B, Klug A (2007) Synaptic transmission at the calyx of Held under in vivo like activity levels. J Neurophysiol 98:807-820.

Hori T, Takahashi T (2009) Mechanisms underlying short-term modulation of transmitter release by presynaptic depolarization. J Physiol 587:2987-3000.

Hsu SF, Augustine GJ, Jackson MB (1996) Adaptation of $\mathrm{Ca}^{2+}$-triggered exocytosis in presynaptic terminals. Neuron 17:501-512.

Inchauspe CG, Forsythe ID, Uchitel OD (2007) Changes in synaptic transmission properties due to the expression of $\mathrm{N}$-type calcium channels at the calyx of Held synapse of mice lacking P/Q-type calcium channels. J Physiol 584:835-851.

Iwasaki S, Takahashi T (2001) Developmental regulation of transmitter release at the calyx of Held in rat auditory brainstem. J Physiol 534:861-871.

Katz B, Miledi R (1968) The role of calcium in neuromuscular facilitation. J Physiol 195:481-492.

Kochubey O, Schneggenburger R (2010) $\mathrm{Ca}^{2+}$ uncaging in nerve terminals. In: Optical imaging in neuroscience: a laboratory manual (Konnerth A, Helmchen F, eds). Cold Spring Harbor, NY: Cold Spring Harbor Laboratory, in press.

Kochubey O, Han Y, Schneggenburger R (2009) Developmental regulation of the intracellular $\mathrm{Ca}^{2+}$ sensitivity of vesicle fusion and $\mathrm{Ca}^{2+}$ - secretion coupling at the rat calyx of Held. J Physiol 587:3009-3023.

Kopp-Scheinpflug C, Fuchs K, Lippe WR, Tempel BL, Rübsamen R (2003) Decreased temporal precision of auditory signaling in Kcnal-null mice: an electrophysiological study in vivo. J Neurosci 23:9199-9207.

Korogod N, Lou X, Schneggenburger R (2005) Presynaptic $\mathrm{Ca}^{2+}$ requirements and developmental regulation of posttetanic potentiation at the calyx of Held. J Neurosci 25:5127-5137.

Liley AW, North KA (1953) An electrical investigation of effects of repetitive stimulation on mammalian neuromuscular junction. J Neurophysiol 16:509-527.

Lorteije JA, Rusu SI, Kushmerick C, Borst JG (2009) Reliability and precision of the mouse calyx of Held synapse. J Neurosci 29:13770-13784.

Lou X, Scheuss V, Schneggenburger R (2005) Allosteric modulation of the presynaptic $\mathrm{Ca}^{2+}$ sensor for vesicle fusion. Nature 435:497-501.

Meyer AC, Neher E, Schneggenburger R (2001) Estimation of quantal size and number of functional active zones at the calyx of Held synapse by nonstationary EPSC variance analysis. J Neurosci 21:7889-7900.

Mochida S, Few AP, Scheuer T, Catterall WA (2008) Regulation of presynaptic $\mathrm{Ca}_{\mathrm{v}} 2.1$ channels by $\mathrm{Ca}^{2+}$ sensor proteins mediates short-term synaptic plasticity. Neuron 57:210-216.

Müller M, Felmy F, Schwaller B, Schneggenburger R (2007) Parvalbumin is a mobile presynaptic $\mathrm{Ca}^{2+}$ buffer in the calyx of Held that accelerates the decay of $\mathrm{Ca}^{2+}$ and short-term facilitation. J Neurosci 27:2261-2271.

Müller M, Felmy F, Schneggenburger R (2008) A limited contribution of $\mathrm{Ca}^{2+}$ current facilitation to paired-pulse facilitation of transmitter release at the rat calyx of Held. J Physiol 586:5503-5520.

Nakamura T, Yamashita T, Saitoh N, Takahashi T (2008) Developmental changes in calcium/calmodulin-dependent inactivation of calcium currents at the rat calyx of Held. J Physiol 586:2253-2261.
Naraghi M, Müller TH, Neher E (1998) Two-dimensional determination of the cellular $\mathrm{Ca}^{2+}$ binding in bovine chromaffin cells. Biophys J 75: 1635-1647.

Neher E, Sakaba T (2001) Combining deconvolution and noise analysis for the estimation of transmitter release rates at the calyx of Held. J Neurosci 21:444-461.

Sakaba T (2006) Roles of the fast-releasing and the slowly releasing vesicles in synaptic transmission at the calyx of Held. J Neurosci 26:5863-5871.

Sakaba T, Neher E (2001) Calmodulin mediates rapid recruitment of fastreleasing synaptic vesicles at a calyx-type synapse. Neuron 32:1119-1131.

Scheuss V, Schneggenburger R, Neher E (2002) Separation of presynaptic and postsynaptic contributions to depression by covariance analysis of successive EPSCs at the calyx of held synapse. J Neurosci 22:728-739.

Schlüter OM, Basu J, Südhof TC, Rosenmund C (2006) Rab3 superprimes synaptic vesicles for release: Implications for short-term synaptic plasticity. J Neurosci 26:1239-1246.

Schneggenburger R, Neher E (2000) Intracellular calcium dependence of transmitter release rates at a fast central synapse. Nature 406:889-893.

Sommer I, Lingenhohl K, Friauf E (1993) Principal cells of the rat medial nucleus of the trapezoid body: an intracellular in vivo study of their physiology and morphology. Exp Brain Res 95:223-239.

Sonntag M, Englitz B, Kopp-Scheinpflug C, Rubsamen R (2009) Early postnatal development of spontaneous and acoustically evoked discharge activity of principal cells of the medial nucleus of the trapezoid body: an in vivo study in mice. J Neurosci 29:9510-9520.

Tang Y, Schlumpberger T, Kim T, Lueker M, Zucker RS (2000) Effects of mobile buffers on facilitation: experimental and computational studies. Biophys J 78:2735-2751.

Taschenberger H, Scheuss V, Neher E (2005) Release kinetics, quantal parameters and their modulation during short-term depression at a developing CNS synapse in the rat. J Physiol 568:513-537.

Tolnai S, Englitz B, Scholbach J, Jost J, Rubsamen R (2009) Spike transmission delay at the calyx of Held in vivo: rate dependence, phenomenological modeling, and relevance for sound localization. J Neurophysiol 102: $1206-1217$.

Trommershäuser J, Schneggenburger R, Zippelius A, Neher E (2003) Heterogeneous presynaptic release-probabilities: functional relevance for short-term plasticity. Biophys J 84:1563-1579.

von Gersdorff H, Schneggenburger R, Weis S, Neher E (1997) Presynaptic depression at a calyx synapse: the small contribution of metabotropic glutamate receptors. J Neurosci 17:8137-8146.

Wadel K, Neher E, Sakaba T (2007) The coupling between synaptic vesicles and $\mathrm{Ca}^{2+}$ channels determines fast neurotransmitter release. Neuron 53:563-575.

Waldeck RF, Pereda A, Faber DS (2000) Properties and plasticity of pairedpulse depression at a central synapse. J Neurosci 20:5312-5320.

Wang LY, Kaczmarek LK (1998) High-frequency firing helps replenish the readily releasable pool of synaptic vesicles. Nature 394:384-388.

Weis S, Schneggenburger R, NeherE (1999) Properties of a model of $\mathrm{Ca}^{2+}$. dependent vesicle pool dynamics and short term synaptic depression. Biophys J 77:2418-2429.

Wölfel M, Lou X, Schneggenburger R (2007) A mechanism intrinsic to the vesicle fusion machinery determines fast and slow transmitter release at a large CNS synapse. J Neurosci 27:3198-3210.

Wu LG, Borst JG (1999) The reduced release probability of releasable vesicles during recovery from short-term synaptic depression. Neuron 23:821-832.

Xu J, Wu LG (2005) The decrease in the presynaptic calcium current is a major cause of short-term depression at a calyx-type synapse. Neuron 46:633-645.

Zucker RS, Regehr WG (2002) Short-term synaptic plasticity. Annu Rev Physiol 64:355-405. 